\title{
Micropercutaneous nephrolithotripsy: initial experience
}

\author{
Erkan Ölçücüoğlu ${ }^{1}$, Yusuf Kasap ${ }^{1}$, Esin Ölçücüoğlu², Mehmet Emin Şirin ${ }^{1}$, Eymen Gazel ${ }^{1}$, Sedat Taştemur ${ }^{1}$, Öner Odabas ${ }^{1}$ \\ 'Department of Urology, Yüksek ihtisas Training and Research Hospital, Ankara, Turkey \\ ${ }^{2}$ Department of Radiology, Yüksek intisas Training and Research Hospital, Ankara, Turkey
}

Videosurgery Miniinv 2015; 10 (3): 368-372

DOI: $10.5114 /$ wiitm.2015.54223

\begin{abstract}
Introduction: For small renal calculi $(<2 \mathrm{~cm})$ the currently available treatment options include extracorporeal shockwave lithotripsy (ESWL), retrograde intrarenal surgery (RIRS) and standard/mini percutaneous nephrolithotomy (PNL). A new method, microperc, has therefore been developed, in which a smaller tract size and smaller instruments were used.

Aim: To present our clinical experiences with micropercutaneous nephrolithotripsy (microperc) in the treatment of small renal calculi.

Material and methods: We retrospectively evaluated patients with small renal calculi who underwent microperc between February and June 2013. A 4.8 Fr 'all-seeing needle' was used to achieve percutaneous renal access with the C-arm fluoroscopy guidance in the prone position. Holmium: YAG laser $272 \mu \mathrm{m}$ fiber was used for stone fragmentation.

Results: $A$ total of 20 patients underwent the microperc procedure. The mean age of the patients was $46.5 \pm 13.8$ years. The mean stone size was $13 \pm 3 \mathrm{~mm}$. The stone-free rate (SFR) was 90\% (18/20). Two patients had clinically significant residual fragments $(\geq 4 \mathrm{~mm})$. The mean operation and fluoroscopy times were $107.5 \pm 37 \mathrm{~min}$ and $45 \pm 40$ s respectively. The mean postoperative drop in hemoglobin was $1.2 \pm 0.9 \mathrm{~g} / \mathrm{dl}$, and 1 patient required blood transfusion. The patients were discharged after an average hospitalization of $1.4 \pm 0.8$ days. Two complications, urinary tract infection and blood loss requiring blood transfusion, were observed in 2 patients postoperatively. Conclusions: We suggest that microperc should be considered for the treatment of small renal stones.
\end{abstract}

Key words: renal, stone, micropercutaneous.

\section{Introduction}

The incidence of urolithiasis is increasing [1], and it is becoming a significant health problem. The objective of the treatment of renal stones is to make the patient stone-free. The treatment options for renal stones are open/laparoscopic surgery, extracorporeal shockwave lithotripsy (ESWL), percutaneous nephrolithotomy (PNL) and retrograde intrarenal surgery (RIRS). For small renal calculi $(<2 \mathrm{~cm})$ the currently available treatment options include ESWL, RIRS and standard/mini PNL. Percutaneous neph- rolithotomy has good stone-free rates (SFR), but it is associated with significant risk of morbidity [2]. The major morbidity from standard PNL is through bleeding [1-5].

Although the standard PNL procedure is generally performed through the 26-30 Fr access tract, mini PNL can be defined as a percutaneous procedure with a tract size of $<18$ Fr. Mini PNL decreases tract-related morbidity [6]. A new method, microperc, has therefore been developed, in which a smaller tract size and smaller instruments are used.

\section{Address for correspondence}

Erkan Ölçücüoğlu MD, PhD, Department of Urology, Yüksek Ihtisas Training and Research Hospital, Kızılay Sokak no: 7 Sihhiye,

06200 Ankara, Turkey, phone: +90 5055170498, e-mail: erkanolcucuoglu@gmail.com 


\section{Aim}

The aim of microperc is to reduce the tract size, as this decreases morbidity [7].

\section{Material and methods}

We retrospectively evaluated patients with small $(1-2 \mathrm{~cm})$ renal calculi who underwent microperc between February and June 2013. A 4.8 Fr 'all-seeing needle' was used to achieve percutaneous renal access with the C-arm fluoroscopy guidance in the prone position. Holmium: YAG laser $272 \mu \mathrm{m}$ fiber was used for stone fragmentation. Residual fragments were defined as having a stone size $\geq 4 \mathrm{~mm}$.

\section{Surgical technique}

The microperc procedure was performed under general anesthesia in the lithotomy position. First, a $7 \mathrm{Fr}$ open-ended ureteral catheter was placed into the renal pelvis. Then the patient was turned to the prone position, and contrast material was delivered through the ureteral catheter in order to delineate the calyceal anatomy. After selection of a suitable calyx, with visualization via fluoroscopy, a 4.8 Fr (16 Gauge) 'all-seeing needle' (PolyDiagnost, Pfaffenhofen, Germany) was advanced into the stone-containing calyx. After insertion of the needle into the collecting system, the optical instrument and the inner sheath were removed and a 3-way connector was applied that enabled insertion of the micro-optic, irrigation system and laser

Table I. Patient demographic values

\begin{tabular}{|lc|}
\hline Characteristics & Value (mean \pm SD) \\
\hline$N$ & 20 \\
\hline Age [years] & $46.5 \pm 13.8$ \\
\hline Male/female & $11 / 9$ \\
\hline Laterality (right/left) & $7 / 13$ \\
\hline Stone size [mm] & $13 \pm 3$ \\
\hline Failure of ESWL, $n$ & 3 \\
\hline Failure of RIRS, $n$ & 20 \\
\hline $\begin{array}{l}\text { Site of stone, } n: \\
\text { Middle calyx }\end{array}$ & 5 \\
\hline Lower calyx & 15 \\
\hline Laterality (right/left) & $6 / 14$ \\
\hline
\end{tabular}

probe. The stones were fragmented using $272 \mu \mathrm{m}$ Holmium: YAG laser (Sphinx, LisaLaser, Katlenburg, Germany) fiber under direct visualization. An irrigation pump was controlled by the surgeon, and drainage of the intrarenal fluid collection was performed using the open-ended ureteral catheter previously positioned. The stone-free status was evaluated with endoscopic and fluoroscopic images at the end of the procedure. The procedure was terminated with no need for a nephrostomy tube. The ureteral catheter removal was carried out on postoperative day 1 for all patients. The SFR was assessed 1 month postoperatively by ultrasound; kidney, ureter and bladder X-ray radiography; and/ or non-contrast computed tomography. Complications were classified according to the Clavien grading system. Patient and operation-related factors were assessed based on perioperative and postoperative parameters. Data were reported as mean \pm standard deviation (SD).

\section{Results}

A total of 20 patients underwent the microperc procedure. The mean age of the patients was 46.5 \pm 13.8 years. The mean stone size was $13 \pm 3 \mathrm{~mm}$ (Table I). All the operations were performed under general anesthesia. The SFR was 90\% (18/20). Two patients had clinically significant residual fragments ( $\geq 4 \mathrm{~mm}$ ). The mean operation and fluoroscopy time was $107.5 \pm 37 \mathrm{~min}$ and $45 \pm 40 \mathrm{~s}$, respectively. The mean postoperative drop in hemoglobin was $1.2 \pm 0.9 \mathrm{~g} / \mathrm{dl}$, while blood transfusion was required for 1 patient. The patients were discharged after an average hospitalization of $1.4 \pm 0.8$ days. Two complications, urinary tract infection and blood transfu-

Table II. Perioperative and postoperative data

\begin{tabular}{|lc|}
\hline Characteristics & $\begin{array}{c}\text { Value } \\
\text { mean } \pm \text { SD } \\
\text { or } n(\%)\end{array}$ \\
\hline Operation time [min] & $111 \pm 37$ \\
\hline Fluoroscopy time [s] & $45 \pm 40$ \\
\hline Duration of hospitalization [days] & $1.4 \pm 0.8$ \\
\hline Hemoglobin drop [g/dl] & $1.2 \pm 0.9$ \\
\hline Stone-free success rate (SFR) (30 days) & $18 / 20(90 \%)$ \\
\hline Complications (Clavien grade II) & $2 / 20(10 \%)$ \\
\hline D-J stent necessary & $3 / 20(15 \%)$ \\
\hline
\end{tabular}


sion (Clavien II), were observed in two patients postoperatively (Table II).

\section{Discussion}

Minimally invasive treatment of kidney stones has evolved dramatically in the last four decades. The aim of minimally invasive surgery with smaller instruments is to achieve low morbidity and mortality, without compromising high SFR.

Goodwin et al. [8] first succeeded in carrying out the placement of a percutaneous nephrostomy tube in the presence of hydronephrosis in 1955. In 1976, PNL was first reported by Fernstrom and Johannson [9]. Since its introduction, several modifications have been made to reduce associated mortality and morbidity, and its effectiveness has been increased by developing novel techniques and improving instrumentation.

Percutaneous nephrolithotomy is the current standard of care for large renal calculi [10]. For small renal calculi $(<2 \mathrm{~cm})$ the currently available management options include ESWL, standard/mini PNL and RIRS. The advantage of PNL is its higher SFR, but the downside is the higher incidence of complications. In the Global Study on PNL from the Clinical Research Office of the Endourological Society, involving 5803 patients, major procedure-related complications including significant bleeding (7.8\%), renal pelvis perforation (3.4\%), hydrothorax (1.8\%) and blood transfusion (5.7\%), were reported [11]. Many of the complications associated with PNL can be attributed to the tract size. It has been shown that blood loss in percutaneous nephrolithotripsy increases with increasing tract size $[5,12,13]$.

While the standard PNL procedure is generally performed through the 26-30 Fr access tract, mini PNL can be defined as a percutaneous procedure with a tract size of $<18 \mathrm{Fr}$. Mini PNL has a smaller hemoglobin drop and a shorter hospital stay but a similar SFR when compared with standard PNL $[14,15]$.

Extracorporeal shockwave lithotripsy has been the treatment of choice for most urinary tract calculi because of its non-invasive nature. The major advantages of ESWL compared to microperc and RIRS are its feasibility with sedoanalgesia and that more than $90 \%$ of stones in adults might be suitable for ESWL treatment [16-18]. Nevertheless, there are certain situations involving complicated stones in which treatment with ESWL is difficult. In particular, anatomical abnormalities, skin-to-stone distance, stone localization (in the lower calyx), and stones of unfavorable composition limit the efficiency of ESWL [19-21].

Extracorporeal shockwave lithotripsy has a lower $\mathrm{SFR}$, and there is a need for repeated sessions, especially with lower polar renal calculi. The reported SFR of ESWL for lower pole calculi is 25-85\%. Extracorporeal shockwave lithotripsy can be compared with endoscopic methods, especially with RIRS. Retrograde intrarenal surgery seems to have a comparable efficacy to ESWL $[22,23]$. Recent clinical experience with the latest generation ureterorenoscopes has suggested that RIRS has an advantage over ESWL. Nonetheless, RIRS comes at the expense of greater invasiveness [24, 25].

Most renal stones of $<20 \mathrm{~mm}$ in diameter are treated by ESWL or by RIRS, although this is being challenged by microperc [26]. The aim of microperc is to reduce the tract size, as this decreases morbidity [5]. The principle of microperc is 'break and leave', without extraction of the fragments. This is similar to ESWL and RIRS.

At the 2010 Congress of the American Urological Association, Bader et al. [27] presented a system for optical control of the puncture through a 16G needle. In their series all cases were subsequently treated by conventional percutaneous surgery. Desai et al. [28] developed the feasibility of the microperc technique. They combined the laser lithotripsy technique with microperc. Their study included 10 patients, and the mean stone size was $14.3 \mathrm{~mm}$. Microperc was feasible in all patients, with a mean hemoglobin drop of $1.4(1.0) \mathrm{g} / \mathrm{dl}$ and a hospital stay of 2.3 (1.2) days. The SFR at 1 month was $88.9 \%$. Hatipoğlu et al. [29] reported a mean hospital stay of $1.76 \pm 0.65$ (1-4) days. The mean hemoglobin drop was $0.87 \pm 0.84$ (04.1) $\mathrm{mg} / \mathrm{dl}$ and the SFR $82 \%$ (115 of 140 cases). Tepeler et al. [26] reported an SFR of $85.7 \%$ (18 out of 21 cases) using microperc in 21 patients with lower pole calculi. In our study the average hospitalization time was $1.4(1-4)$ days and the mean hemoglobin drop was $1.2 \pm 0.9 \mathrm{~g} / \mathrm{dl}$. These results were found to be consistent with the literature. In their meta-analysis, De et al. compared minimally invasive percutaneous procedures (MIPP: Mini PNL and microperc) to RIRS in terms of hospitalization time, operation time, complication rates and SFR. They found similar complication rates in MIPP and RIRS. Although RIRS has a shorter hospitalization time, MIPP has a shorter operation time and a higher SFR [30]. 
Recent literature has reported an SFR for micro-PNL ranging from $85 \%$ to $93 \%[26,28,31]$. In our study an average successful SFR of $90 \%$ was obtained. Silay et al. [32] demonstrated the successful use of microperc for small $(<2 \mathrm{~cm})$ renal stones in children and infants. Sabnis et al. [33] reported that microperc is a safe, effective alternative to RIRS for the management of small renal calculi, and that microperc has a similar SFR to RIRS (microperc: $97.1 \%$; RIRS: $94.1 \% ; p=1.0)$. Microperc's complication rates when compared to RIRS are associated with higher hemoglobin loss, increased pain and higher analgesic requirements. However, RIRS is associated with a higher requirement for double J stenting.

With regard to the limitations of this study, its retrospective nature and the small number of cases presented constitute the main concerns. We believe that despite these limitations, the present study will contribute to the literature. Prospective randomized comparative studies are however needed before a consensus can be reached about which treatment modality is more effective and less invasive.

\section{Conclusions}

Most of the authors have proposed microperc as an alternative to PNL, ESWL and RIRS for the treatment of patients with small renal stones $(1-2 \mathrm{~cm})$. Our results show that microperc is a safe and effective procedure in the treatment of small renal stones.

\section{Conflict of interest}

The authors declare no conflict of interest.

\section{References}

1. Dwyer ME, Krambeck AE, Bergstralh EJ, et al. Temporal trends in incidence of kidney stones among children: a 25-year population based study. J Urol 2012; 188: 247-52.

2. Michel MS, Trojan L, Rassweiler JJ. Complications in percutaneous nephrolithotomy. Eur Urol 2005; 51: 899-906.

3. Doré B. Complications of percutaneous nephrolithotomy: risk factors and management. Ann Urol (Paris) 2006; 40: 149-60.

4. Skolarikos A, de la Rosette J. Prevention and treatment of complications following percutaneous nephrolithotomy. Curr Opin Urol 2008; 18: 229-34.

5. Kukreja R, Desai M, Patel S, Bapat S. Factors affecting blood loss during percutaneous nephrolithotomy: prospective study. J Endourol 2004; 18: 715-22.

6. Helal M, Black T, Lockhart J, Figueroa TE. The Hickman peelaway sheath: alternative for pediatric percutaneous nephrolithotomy. J Endourol 1997; 11: 171-2.
7. Desai MR, Jain P, Ganpule AP, et al. Developments in technique and technology: the effect on the results of percutaneous nephrolithotomy for staghorn calculi. BJU Int 2009; 104: 542-8.

8. Goodwin WE, Casey WC, Woolf W. Percutaneous trocar (needle) nephrostomy in hydronephrosis. J Am Med Assoc 1955; 157: 891-4.

9. Fernstrom I, Johansson B. Percutaneous pyelolithotomy. A new extraction technique. Scand J Urol Nephrol 1976; 10: 257-9.

10. Preminger GM, Assimos DG, Lingeman JE, et al. Chapter 1: AUA guideline on management of staghorn calculi: diagnosis and treatment recommendations. J Urol 2005; 173: 1991-2000.

11. De la Rosette J, Assimos D, Desai M, et al. The Clinical Research Office of the Endourological Society Percutaneous Nephrolithotomy Global Study: indications, complications, and outcomes in 5803 patients. J Endourol 2011; 25: 11-7.

12. Yamaguchi A, Skolarikos A, Buchholz NP, et al. Operating times and bleeding complications in percutaneous nephrolithotomy: a comparison of tract dilation methods in 5,537 patients in the Clinical Research Office of the Endourological Society Percutaneous Nephrolithotomy Global Study. J Endourol 2011; 25: 933-9.

13. Cheng $F, Y u W$, Zhang $X$, et al. Minimally invasive tract in percutaneous nephrolithotomy for renal stones. J Endourol 2010; 24: 1579-82.

14. Mishra S, Sharma R, Garg C, et al. Prospective comparative study of miniperc and standard PNL for treatment of 1 to $2 \mathrm{~cm}$ size renal stone. BJU Int 2011; 108: 896-9.

15. Sabnis RB, Ganesamoni R, Sarpal R. Miniperc: what is its current status? Curr Opin Urol 2012; 22: 129-33.

16. Wen CC, Nakada SY. Treatment selection and outcomes: renal calculi. Urol Clin North Am 2007; 34: 409-19.

17. Miller NL, Lingeman JE. Management of kidney stones. BMJ 2007; 334: 468-72.

18. Galvin DJ, Pearle MS. The contemporary management of renal and ureteric calculi. BJU Int 2006; 98: 1283-8.

19. Albala DM, Assimos DG, Clayman RV, et al. Lower pole I: a prospective randomized trial of extracorporeal shock wave lithotripsy and percutaneous nephrostolithotomy for lower pole nephrolithiasis initial results. J Urol 2001; 166: 2072-80.

20. Patel T, Kozakowski K, Hruby G, Gupta M. Skin to stone distance is an independent predictor of stone-free status following shockwave lithotripsy. J Endourol 2009; 23: 1383-5.

21. Wiesenthal JD, Ghiculete D, D’A Honey RJ, Pace KT. Evaluating the importance of mean stone density and skin-to-stone distance in predicting successful shock wave lithotripsy of renal and ureteric calculi. Urol Res 2010; 38: 307-13.

22. Preminger GM. Management of lower pole renal calculi: shock wave lithotripsy versus percutaneous nephrolithotomy versus flexible ureteroscopy. Urol Res 2006; 34: 108-11.

23. Pearle MS, Lingeman JE, Leveillee R, et al. Prospective, randomized trial comparing shock wave lithotripsy and ureteroscopy for lower pole caliceal calculi $1 \mathrm{~cm}$ or less. J Urol 2005; 173: 2005-9.

24. Hussain M, Acher P, Penev B, Cynk M. Redefining the limits of flexible ureterorenoscopy. J Endourol 2011; 25: 45-9.

25. Wendt-Nordahl G, Mut T, Krombach P, et al. Do new generation flexible ureterorenoscopes offer a higher treatment success than their predecessors? Urol Res 2011; 39: 185-8. 
26. Tepeler A, Armagan A, Sancaktutar AA, et al. The role of microperc in the treatment of symptomatic lower pole renal calculi. J Endourol 2013; 27: 13-8.

27. Bader MJ, Gratzke C, Seitz M, et al. The 'all-seeing needle'. Initial results of an optical puncture system confirming access in percutaneous nephrolithotomy. Eur Urol 2011; 59: 1054-9.

28. Desai MR, Sharma R, Mishra S, et al. Single step percutaneous nephrolithotomy (microperc): the initial clinical report. J Urol 2011; 186: 140-5.

29. Hatipoğlu NK, Tepeler A, Buldu I, et al. Initial experience of micro-percutaneous nephrolithotomy in the treatment of renal calculi in 140 renal units. Urolithiasis 2014; 42: 159-64.

30. De S, Autorino R, Kim FJ, et al. Percutaneous nephrolithotomy versus retrograde intrarenal surgery: a systematic review and meta-analysis. Eur Urol 2014; 5729: 13.

31. Piskin MM, Guven S, Kilinc M, et al. Preliminary, favorable experience with microperc in kidney and bladder stones. J Endourol 2012; 26: 1443-7.

32. Silay MS, Tepeler A, Atis G, et al. Initial report of microperc in the treatment of pediatric nephrolithiasis. J Pediatr Surg 2013; 48: 1578-83.

33. Sabnis, RB, Ganesamoni R, Doshi A, et al. Micropercutaneous nephrolithotomy (microperc) vs retrograde intrarenal surgery for the management of small renal calculi: a randomized controlled trial. BJU International 2013; 112: 355-61.

Received: 15.01.2015, accepted: 9.06.2015 